\title{
Teachers' Perceptions and Practices of Active Learning in Haramaya University, Eastern Ethiopia: The Case of Faculty of Education
}

\author{
Aschalew Teshome \\ Department of Special Needs Education, College of Education and Behavioral Sciences, \\ Haramaya University, Ethiopia
}

\begin{tabular}{|c|c|}
\hline Abstract & Article Information \\
\hline \multirow{11}{*}{$\begin{array}{l}\text { The purpose of this study was to investigate instructors' perceptions and practices } \\
\text { of active learning, assess the extent to which instructors' perceptions influence } \\
\text { their practices and identify factors affecting the implementation of active learning } \\
\text { in Haramaya University faculty of education. To conduct the study, descriptive } \\
\text { survey design was employed. A total of } 123 \text { instructors participated in the study } \\
\text { and completed questionnaires. This was complemented by a qualitative approach } \\
\text { that used observation checklists and interviews for data gathering: } 9 \text { lessons were } \\
\text { observed while the instructors were teaching in the actual classes. In addition, } \\
\text { semi-structured interviews were conducted with three instructors. In the selection } \\
\text { of the sample population, purposive and systematic samplings were used. The } \\
\text { data were analyzed using percentage, mean and grand mean. The findings of the } \\
\text { study revealed that the respondents have perceived active learning positively. In } \\
\text { spite of their good perceptions, their practices of active learning were low. Among } \\
\text { the major factors affecting the effective implementation of active learning were } \\
\text { instructors' tendency toward the traditional/lecture method, lack of students' } \\
\text { interest, shortage of time, lack of instructional material and large class size. } \\
\text { Finally, recommendations were forwarded based on the major findings so as to } \\
\text { minimize problems encountered and maximize the implementation of active } \\
\text { learning in the study area. }\end{array}$} & $\begin{array}{ll}\text { Received } & : 25-09-2012 \\
\text { Revised } & : 15-12-2012 \\
\text { Accepted } & : 20-12-2012 \\
\end{array}$ \\
\hline & Keywords: \\
\hline & Active learning \\
\hline & Student centered approache \\
\hline & Teacher centered approache \\
\hline & Instructors perceptions \\
\hline & Active learning practices \\
\hline & ${ }^{*}$ Corresponding Author: \\
\hline & Aschalew Teshome \\
\hline & E-mail: \\
\hline & aschalew.teshome@yahoo.com \\
\hline
\end{tabular}

\section{INTRODUCTION}

We live in a dynamic world where everything is changing. As a result, what we think true today may be false tomorrow and what we think false today may be true tomorrow. Hence, we have to adjust ourselves to the changing world or modify it to fit our needs. It is education that enables us to do so. This means that education enables us to lead a better life in this dynamic world. In this respect, education has passed through continuous change (Aggarwal, 2006).

Until recently education has been considered as a banking method in which the bank is a learner's mind and the possessor of the knowledge is the teacher (Freire, 2003). This idea is still widely felt by the people who think that knowledge can be pumped into the learner like petrol into a tank and that when he/she is full he/she is educated. The error of this assumption is that learning is a passive process in which the teacher does the filling and the learner is filled. But this has made the learners passive which is the case of teacher-centered approach (Aggarwal, 2006; Freire, 2003).

However, the idea that students are passive recipients of knowledge and that teachers are the transmitters of that knowledge is giving way to the notion that students learn better when they are involved in the process of creating knowledge for themselves. Moreover, the goals of education encompass not only the acquisition of knowledge but also the guidance of the individual to his/her fullest potential. The latter involves the development of a multitude of skills- skills of critical thinking, of independent inquiry and of group participatory behavior (Clark et al., 2008). 


\section{Aschalew Teshome}

In this regard, many theorists and practitioners have attempted to make what goes on in the classroom more consistent with the reality of the world outside the classroom. They urge us to give greater recognition to the various skills needed to function in the society as human being, worker, citizen, consumer and parent to develop a more sophisticated awareness of the uses of knowledge ; and to become concerned not only with knowing about but also in knowing how (learning to learn). Similarly, Good and Brophy (2006) reported that one important variable that contributed to students' achievement is the involvement of students in organizing and planning their own instruction. This is to say that the learner learns more if he/she does or participates in the learning activities and he/she does and learn if what he/she learns goes with his/her needs, interest and ability level.

It is from this point of view that many educators support active learning approach in education and greater attention has been given to shift the teacher-centered approach to a studentcentered one. This is also true in case of Ethiopia that the new Education and Training Policy of 1994 promotes the need for active learning approach in the classroom so as to:

- develop the physical and mental potential and the problem-solving capacity of individuals by expanding education in particular and by providing basic education for all;

- educate citizens who can take care of and utilize resources wisely, who are trained in various skills by raising the private and social benefits of education;

- educate citizens who respect human rights, stand for the well-being of people, as well as for equality, justice and peace, endowed with a democratic culture and discipline;

- educate citizens to differentiate harmful practices from useful ones, to seek and stand for truth, appreciate aesthetics and show positive attitudes towards the development and dissemination of science and technology in society and

- cultivate the cognitive, creative, productive and appreciative potential of citizens by appropriately relating education to environmental and societal needs (MOE, 2002).

The realization of the above listed educational objectives of the country requires an approach that gives opportunities for active involvement, participation and creativity of students, which in turn necessitates the use of effective pedagogical
Sci. Technol. Arts Res. J., Oct-Dec 2012, 1(4):74-83

and psychological approaches to meet the demands of the new generation.

In this regard, universities are important places where educational objectives are to be achieved effectively and efficiently. Haramaya University $(\mathrm{HU})$ is one of the oldest and a forerunner university in Ethiopia which produces competent graduates' who can understand the essence of education and its implication in the actual life situation to enhance the existing society guided by the new education and training policy of the country. Hence, teachers are agents to achieve the general objectives of the new education and training policy, they should have to exercise the approach being praised by the policy. However, there are some constraints which can impede the proper implementation of active-learning approaches in this university. Some of the factors are connected with the pressure of the curriculum, improper classroom organization and management, lack of trained teachers, lack of support from top officials, perceptions of active learning and the problem with the students (Plass, 2008, Leu, 2000).

Some local studies were conducted in relation to the implementation of active learning in universities, colleges and some government schools of Ethiopia. Among them is "The Implementation of Active Learning, Case of Kotebe College of Teacher Education" by Tibebu Tekletsadik in 2006. His major finding indicates that the magnitude of practicing active learning is very low. The other study conducted by Oli Negassa in the same year was entitled "The status of Active Learning Approach in the Teacher Education Colleges of Oromia Region." His study revealed that the use of active learning practice in the teacher education colleges varied. Yet, another researcher, Yonas Amdemeskel conducted a case study on factors that affect the implementation of active learning in primary schools of west Harerghe. The study reported that large class size, shortage of instructional material, lack of skills in selecting a variety of methods and lack of awareness on what active learning is, are the major factors that affect the implementation of active learning. However, none of these studies were actually intended to examine teachers' perceptions of their practices and challenges they encountered on the implementation of active learning in universities. Therefore, it is with this intention that the researcher is initiated and motivated to conduct a research in Haramaya University, Faculty of Education. 


\section{Aschalew Teshome}

It is quite evident that the active involvement of the students in classroom and outside the classroom teaching-learning process enables them to develop critical thinking skills. Nardos (2000) explains that active learning is likely to be enjoyed, offers opportunity for progress, and thereby fosters positive students' attitudes towards the subjects. Similarly, Silberman (2006) reminds us that real learning is not memorization. Most of what we memorize is lost in hours. That is, learning cannot be swallowed. In order to retain what has been taught, students must put together what they hear and see into a meaningful whole. Together, research and experience indicate that active learning leads to effective teaching- learning to bring about the expected behavioral change.

The Education and Training Policy and the existing curriculum of Ethiopia call for activelearning. The curriculum reforms initiated imply a shift from passive-learning to more active education (Leu, 2000). As indicated in the policy document of the Transitional Government of Ethiopia (1994), the previous curriculum design and instructional processes suffered from old and traditional approaches. There have been continuous revisions in the instructional approaches to offer quality training and make the active learning practical.

In addition, the policy document entitled "Teacher Education System Overhaul (TESO)" program was introduced in 2003. In this document, among other major programs, one emphasizes the implementation of participatory, active learning in the pre-service and in-service programs of higher education institutions of Ethiopia (MOE, 2003).

However, it is hypothesized that there are different factors affecting the practices of activelearning. From the interview conducted with 20 teachers who attended the higher diploma program in Haramaya University in 2009/10, there is evidence that large class size, unfavorable classroom environment /conditions, lack of instructional resource/materials, students previous experience, interest of students and teachers, misconceptions/lack of knowledge about the approaches, time constraint and teachers work load are some of the factors that hinder the effective implementation of active learning approaches in Haramaya University.

In order to make the learning-teaching process more relevant to the immediate needs of the students, society, and the nation at large, it is imperative to improve the quality of education in
Sci. Technol. Arts Res. J., Oct-Dec 2012, 1(4):74-83

Ethiopia through direct involvement of students in active learning approaches as a means of rectifying the differences in their educational backgrounds. However, as stated above, little research has been carried out in exploring the issue of active learning approaches in higher education especially teachers' perceptions of their practices and challenges they encountered while implementing active learning. Hence, the researcher believes that this study will be helpful to fill the existing gap in current research and aims to explore the nature of the teachinglearning process in line with the active learning approaches and identify the major challenges /factors that hinder its effectiveness in Haramaya University Faculty of Education.

The Ethiopian Education and Training Policy has widely been advocating active learning approaches (Melese, 2009; MOE, 2002). The results of this study will provide information on the problems that are currently experienced in implementing active learning approaches at the University of Ethiopia. These results may be pivotal for implementing the education and training policy in general and in instructional processes in particular. The results may also provide recommendations for solutions to problems experienced. Since the authorities at the various levels of educational administration are responsible for creating conducive working environments in educational institutions and for guiding practitioners, they may also benefit from the findings of the present study. In view of the above, this study will help university lecturers, students, academic department heads, deans, the Ministry of Education, the Regional Education Bureau, Woreda Education Office and other concerned bodies to design measures for addressing the possible problems related to the implementation of active learning approaches in universities. Finally, the study may serve as a stepping-stone for further and more extensive research in the area of active learning approaches by identifying areas that need further research.

\section{MATERIALS AND METHODS}

The study attempts to describe instructors' perceptions and practices of active learning, assess how the perceptions of instructors influence their practices of active learning and identify factors that affect the implementation of active learning in Haramaya University, Faculty of Education. Thus, descriptive survey was chosen as it enables the researcher to describe the current status of the study area. According to the information obtained from the academic vice 


\section{Aschalew Teshome}

president office of the University (2009), there exist 180 instructors in the former faculty of education. 120 instructors were selected by using systematic random sampling. In order to secure additional information, three classes were observed three times. Furthermore, the three observed instructors were selected and interviewed purposely. All together 123 instructors were included in the study.

Questionnaire, observation and interview were the primary tools of data collection. The questionnaire was prepared and completed by 120 instructors from the former faculty of education. The researcher validated the instruments that were developed as follows: before the actual data collection was started the instruments were given to colleagues so as to get valuable comments and criticisms on the strengths and weaknesses of the items. Based on the comments obtained, necessary modifications were made. To obtain more information, observation in the actual classroom teaching and learning process was used as a data gathering instrument. For the purpose of observation, a checklist was employed. The observations were focusing on teacher- student interaction in relation to active learning, classroom facility, student population in the classroom, instructors' and students' activities. To supplement the data obtained through questionnaire the researcher conducted interviews with four instructors using open- ended questions, which are related to the knowledge and practices of active learning.

The researcher adopted three steps in collecting the data for the study. First, relevant literature was reviewed to get adequate information on the topic. Second, objectives and research questions were formulated to show the direction of the study. Third, data gathering tools were developed and piloted. After the questionnaire was distributed and collected, classroom observations took place. Finally, the interview with instructors was conducted. The data obtained from instructors through questionnaires, observations and interviews were analyzed using descriptive analysis method and the result of the study is reported using percentages, mean and grand mean obtained from the numerical values assigned to the degree of agreement. Finally, based on the findings of the study, conclusions were drawn and recommendations were forwarded.
Sci. Technol. Arts Res. J., Oct-Dec 2012, 1(4):74-83

\section{RESULTS AND DISCUSSION}

Using the questionnaire administered to teachers, responses about their perceptions of active learning were calculated and presented. The data taken from the surveys were analyzed in line with the research questions. In analyzing the perceptions of instructors on active learning, a questionnaire entitled "Knowledge and experience on active learning" served as the primary source of information.

Active learning demands not only teachers to be experts in their fields but also they have to understand how students learn best. Accordingly, items related to assumptions about active learning, advantages of active learning and their views about active learning were presented to find out their perceptions. Item 1 says "Current knowledge depends on the previous understanding." It was widely supported by the instructors. As can be seen in table 1, the mean value of their responses (4.5) ranges from "Agree" to "Strongly Agree." Hence, all the instructors agreed on the idea (assumption) that current knowledge depends on the previous knowledge or understanding.

On the other hand item 2 of the same table says "The teacher holds most of the knowledge necessary for the students." The mean value for this response is between 1 and 2, i.e., the instructors reflected their strong disagreement. This implies that all the instructors believe that students can also be sources of knowledge. Item 4 encountered strong disagreement by $100 \%$ of the instructors. This means that teaching facts alone is not enough to prepare students to understand their environment. For items 5 and 6 the mean values of the responses are 4.83 each. This indicates that instructors strongly agreed on the issues which say teachers must prepare students to communicate. Item 9 says "Active learning offers opportunities for progress." Regarding this item almost all $(91.7 \%)$ of the respondents showed their strong agreement with the issue. Furthermore, the mean value of the responses (4.92) strengthens the support to the assumption raised. Item 13 says "Active learning is not economical to use instructional aids." A high percentage $(75 \%)$ of the respondents disagreed with the statement.

Item 14 of the same table is about the requirement of active learning. Fifty percent of the respondents strongly disagreed with the idea and the other $50 \%$ of respondents supported the idea. But the mean value of the responses tends to disagree with the issue. The general analysis of 
Table 1: Frequency Distribution and Mean Values of Data Collected on Perceptions of Instructors.

\begin{tabular}{|c|c|c|c|c|c|c|c|c|c|c|c|c|}
\hline \multirow{2}{*}{ Items } & \multicolumn{2}{|c|}{$\begin{array}{c}1=\mathrm{S} \text {. Dis } \\
\text { agree }\end{array}$} & \multicolumn{2}{|c|}{$\begin{array}{c}2= \\
\text { Disagree }\end{array}$} & \multicolumn{2}{|c|}{$\begin{array}{c}3= \\
\text { Undecided }\end{array}$} & \multicolumn{2}{|c|}{ 4= Agree } & \multicolumn{2}{|c|}{$5=$ S.Agree } & \multirow{2}{*}{$\left(\sum \mathbf{V x f}\right)$} & \multirow{2}{*}{$X=\frac{\sum V x f}{N}$} \\
\hline & $f$ & $\%$ & $f$ & $\%$ & $f$ & $\%$ & $f$ & $\%$ & $f$ & $\%$ & & \\
\hline 1 & & & & & & & 60 & 50 & 60 & 50 & 540 & 4.5 \\
\hline 2 & 60 & 50 & 50 & 41.7 & 10 & 8.3 & & & & & 190 & 1.6 \\
\hline 3 & & & 60 & 50 & & & & & 60 & 50 & 420 & 3.5 \\
\hline 4 & 120 & 100 & & & & & & & & & 120 & 1 \\
\hline 5 & & & & & & & 20 & 16.7 & 100 & 83.3 & 580 & 4.83 \\
\hline 6 & & & & & & & 20 & 25 & 100 & 75 & 580 & 4.83 \\
\hline 7 & & & & & & & 60 & 50 & 60 & 50 & 540 & 4.5 \\
\hline 8 & & & & & & & 90 & 75 & 30 & 25 & 510 & 4.25 \\
\hline 9 & & & & & & & 10 & 8.3 & 110 & 91.7 & 590 & 4.92 \\
\hline 10 & & & & & & & 90 & 75 & 30 & 25 & 510 & 4.25 \\
\hline 11 & & & & & & & 20 & 16.7 & 100 & 83.3 & 580 & 4.83 \\
\hline 12 & 20 & 16.7 & 100 & 83.3 & & & & & & & 220 & 1.83 \\
\hline 13 & 30 & 25 & 90 & 75 & & & & & & & 210 & 1.75 \\
\hline 14 & 60 & 50 & & & & & 60 & 50 & & & 320 & 2.67 \\
\hline 15 & & & & & & & 60 & 50 & 60 & 50 & 540 & 4.5 \\
\hline 16 & 60 & 50 & & & & & 60 & 50 & & & 320 & 2.67 \\
\hline $\begin{array}{c}\text { G. } \\
\text { Mean }\end{array}$ & & & & & & & & & & & & 3.53 \\
\hline
\end{tabular}

all the items indicates that most instructors seem to have positive attitudes towards active learning. The grand mean value (3.53) of all the responses tends to support the values for agree. Hence, one can deduce that the groups of instructors have perceived active learning positively. The instructors' positive perception of active learning is strengthened by the interview conducted with them.

Various research findings confirmed that there is a strong tie between instructors' attitudes towards active learning and their effort in implementing it. For instance, a survey study carried out in Botswana in 2009 proved that instructors who had a positive attitude towards active learning showed a better effort in implementing and using active learning than those instructors who perceived active learning negatively (GDE, 2009). Similarly, Sguazzin and Grann (2008) showed that teachers' attitudes have a great influence in the effective implementation of active learning. In line with these ideas, sixteen statements for the instructors were included in the questionnaires with the intention of assessing their knowledge or perception of active learning. Hence, it appeared that almost all of the instructors showed their agreement and strong agreement with the assumption of active learning raised in the questionnaires.

The level of their agreement with the assumptions of active learning shows us that the instructors have perceived active learning positively. But their positive perception doesn't let them practice active learning in their classroom. This was also witnessed during the classroom observation.

Various research findings confirmed that there is a strong tie between instructors' attitudes towards active learning and their effort in implementing it. For instance, a survey study carried out in Botswana in 2009 proved that instructors who had a positive attitude towards active learning showed a better effort in implementing and using active learning than those instructors who perceived active learning negatively (GDE, 2009). Similarly, Sguazzin and Grann (2008) showed that teachers' attitudes have a great influence in the effective 


\section{Aschalew Teshome}

implementation of active learning. In line with these ideas, sixteen statements for the instructors were included in the questionnaires with the intention of assessing their knowledge or perception of active learning. Hence, it appeared that almost all of the instructors showed their agreement and strong agreement with the assumption of active learning raised in the questionnaires.
Sci. Technol. Arts Res. J., Oct-Dec 2012, 1(4):74-83

The level of their agreement with the assumptions of active learning shows us that the instructors have perceived active learning positively. But their positive perception doesn't let them practice active learning in their classroom. This was also witnessed during the classroom observation.

Table 2: Frequency and Mean Values of Instructors' use of Active Learning Strategies.

\begin{tabular}{|c|c|c|c|c|c|c|c|c|c|c|c|c|}
\hline \multirow{2}{*}{ Items } & \multicolumn{2}{|c|}{$\begin{array}{c}1=\text { Not } \\
\text { at all }\end{array}$} & \multicolumn{2}{|c|}{ 2= Rarely } & \multicolumn{2}{|c|}{$\begin{array}{c}3=\text { Some } \\
\text { times }\end{array}$} & \multicolumn{2}{|c|}{$\begin{array}{c}4= \\
\text { Frequently }\end{array}$} & \multicolumn{2}{|c|}{$5=$ Always } & \multirow{2}{*}{$(\Sigma \mathbf{V x f})$} & \multirow{2}{*}{$\underset{X=-{ }_{X x f}}{N}$} \\
\hline & $f$ & $\%$ & f & $\%$ & $f$ & $\%$ & $f$ & $\%$ & $f$ & $\%$ & & \\
\hline 1 & & & & & 110 & 91.7 & 10 & 8.3 & & & 370 & 3.1 \\
\hline 2 & & & 20 & 16.7 & 100 & 83.3 & & & & & 340 & 2.83 \\
\hline 3 & & & & & 60 & 50 & & & 60 & 50 & 480 & 4 \\
\hline 4 & & & & & 60 & 50 & 60 & 50 & & & 420 & 3.5 \\
\hline 5 & & & & & & & 20 & 16.7 & 100 & 83.3 & 580 & 4.83 \\
\hline 6 & & & & & & & & & 120 & 100 & 600 & 5 \\
\hline 7 & & & & & 10 & 8.3 & 110 & 91.7 & & & 470 & 3.92 \\
\hline 8 & & & & & 20 & 16.7 & 100 & 83.3 & & & 460 & 3.83 \\
\hline 9 & 100 & 83.3 & 20 & 16.7 & & & & & & & 140 & 1.2 \\
\hline 10 & & & & & & & 60 & 50 & 60 & 50 & 540 & 4.5 \\
\hline 11 & & & & & & & 30 & 25 & 90 & 75 & 570 & 4.75 \\
\hline 12 & & & & & 60 & 50 & 60 & 50 & & & 420 & 3.5 \\
\hline 13 & & & & & 60 & 50 & & & 60 & 50 & 480 & 4 \\
\hline $\begin{array}{c}\text { G. } \\
\text { Mean }\end{array}$ & & & & & & & & & & & & 3.77 \\
\hline
\end{tabular}

As can be seen from table 2, different active learning strategies were provided as representatives. Accordingly, the frequency distribution of the use of these strategies by respondents is presented as follows.

The first one is teacher focused method, which is "lecture/ explanation" based. It was reflected by almost all $(91.7 \%)$ of the instructors that it has been used sometimes. The mean value of the responses (3.1) indicates the same. In response to the item 1 instructors' pretended that they use lecture method only some times. But the observation result reveals that they tend to use the lecture method frequently. On the other hand, among common active learning strategies presented in table 2, 'Discussion' was answered by $83.3 \%$ of the respondents. The method is employed 'always'. The mean value for discussion is (4.83). This value also indicates frequent use of discussion in the University under study.

The other active learning strategy favored by all the instructors was 'Brain storming'. The mean value (5.0) indicates that all the instructors use 'Brain storming' always. The mean value for 'Peer-Teaching' (3.92) is very nearly close to the values for 'Frequently'. This value also indicates that the instructors employ this strategy in their classrooms frequently. Another commonly used active learning strategy, "Group work" is indicated by the mean value of 4.5 . The mean value shows that the active learning strategy is used by the instructors frequently. In the same way 'Debating' is frequently employed by the instructors. The grand mean (3.77) is approaching 4 which is equal to the value for 'frequently'. From the instructors' responses, therefore, one can say that active learning is frequently employed in the 


\section{Aschalew Teshome}

University. Nevertheless, the observation results and some interviewees' responses disprove this.

To assess the extent to which active learning has been practically implemented in the University, instructors reacted either through questionnaire or the interview. To substantiate the data, structured observation was also made. Accordingly, the instructors identified the frequency with which they implement active learning from the responses of the questionnaire, observation and interview. These data indicate that the instructors implement active learning occasionally in their classroom. The responses of the instructors to questions related to their use of active learning were validated by the responses of the students.

The most frequently practiced active learning strategies reported by the instructors were group work, discussion, role-playing, peer-teaching and cooperative learning. These methods were employed widely because most probably the instructors were familiarized with the methods. But these strategies especially, discussion and group work can help to develop only lower levels
Sci. Technol. Arts Res. J., Oct-Dec 2012, 1(4):74-83

of cognitive domain. On the other hand, other active learning strategies related to higher level of cognitive domain believed to develop critical thinking and problem solving capacity of the students were not widely practiced.

In line with this, Bonweel and Eison (2003) noticed that students must do more than just listen. They need to read, write, discuss or engage in problem solving activities. In real active learning model, students must be engaged in higher order thinking skills as synthesis, analysis and evaluation. Again strong relationships established between the perception of instructors and students group work and discussion. In general, instructors agreed that active learning practice takes place sometimes. Finally, the remaining active learning strategies, role-play, debating, cooperative learning are practiced sometimes in the University as depicted in the finding. Based on the position of the respondents and the interview and observation made by the researcher, it is possible to infer that the extent of the practice of active learning in the University is low.

Table 3: Percentage and Mean Values of Factors Affecting Instructors' Implementation of Active Learning.

\begin{tabular}{|c|c|c|c|c|c|c|c|c|}
\hline \multirow[b]{2}{*}{ Items } & \multicolumn{2}{|c|}{$1=$ Not Serious } & \multicolumn{2}{|c|}{$2=$ Serious } & \multicolumn{2}{|c|}{$3=$ Most serious } & \multirow{2}{*}{$(\Sigma \mathbf{V x f})$} & \multirow{2}{*}{$X=\frac{\sum V x f}{N}$} \\
\hline & $f$ & $\%$ & $f$ & $\%$ & $f$ & $\%$ & & \\
\hline 1 & 40 & 33.3 & 20 & 16.7 & 60 & 50 & 260 & 2.20 \\
\hline 2 & 60 & 50 & 50 & 41.6 & 10 & 8.4 & 180 & 1.50 \\
\hline 3 & 50 & 41.6 & 60 & 50 & 10 & 8.4 & 200 & 1.70 \\
\hline 4 & 90 & 75 & 10 & 8.4 & 20 & 16.6 & 170 & 1.42 \\
\hline 5 & 90 & 75 & 30 & 25 & & & 150 & 1.25 \\
\hline 6 & 90 & 75 & 10 & 8.4 & 20 & 16.6 & 170 & 1.42 \\
\hline 7 & 10 & 8.4 & 30 & 25 & 80 & 77.6 & 310 & 2.53 \\
\hline 8 & 10 & 8.4 & 30 & 25 & 80 & 77.6 & 310 & 2.53 \\
\hline 9 & 60 & 50 & 60 & 50 & & & 180 & 1.50 \\
\hline 10 & 90 & 75 & 30 & 25 & & & 150 & 1.25 \\
\hline 11 & 100 & 83.3 & 20 & 16.4 & & & 140 & 1.20 \\
\hline 12 & 60 & 50 & 50 & 41.6 & 10 & 8.4 & 180 & 1.50 \\
\hline $\begin{array}{c}\text { G. } \\
\text { Mean }\end{array}$ & & & & & & & & 2 \\
\hline
\end{tabular}

Table 3 shows factors affecting instructors' implementation of active learning. In this part there were twelve factors assumed to be affecting factors in the implementation of active learning.
Among these factors, the researcher has selected five of the factors to discuss instructors' tendency to use traditional/ lecture method, students' lack of interest in active learning, 


\section{Aschalew Teshome}

students' belief and perception, large class size and instructors' belief and perception. The factors are selected because they are indicated by the respondents to be factors that significantly affect the implementation of active learning.

There is no question that interest, belief and perceptions are crucial factors in implementing active learning in classrooms. As can be seen from table 3 , one of the hindering factors for the implementation of active learning is a lack of students' interest in active learning. This factor is proposed by $50 \%$ of the instructors as a serious one. Another negatively affecting factor of the implementation of active learning proposed by the instructors is students' belief and perception. According to the instructors' interview, students do not like to be taught by active learning method. Hence, instructors found it difficult to implement active learning.

It is also very difficult to apply active learning in large classes and in a situation where there is negative perception the teachers/instructors become reluctant. In line with this, $77.6 \%$ of the instructors identified that large class size and perception of the teachers are the most serious factors affecting the implementation of active learning.

Like any other educational issue in the teaching-learning process, it is also possible to think that active learning may have shortcomings or constraints during its implementation in the real classroom conditions. Of these constraints, the researcher has selected five of the most serious possible factors affecting the implementation of active learning in the University. These factors are selected on the basis of their frequencies in the responses of the instructors and students. Shortage of time is among these factors. With respect to this problem the respondents agreed that the time table was the major problem negatively affecting the implementation of active learning. Supporting this fact, Farant (2000) explains the effect of time by stressing that shortage of time limits instructors and students from implementing active learning in the classroom.

In this study, the instructors' tendency towards traditional lecture method is blamed as an obstacle in the implementation of active learning by instructors. With respect to this problem, the respondents again agreed that the tendency of instructors and students to the traditional methods of teachers' explanation or lecture was the major problem negatively influencing the effective implementation of active learning. In this
Sci. Technol. Arts Res. J., Oct-Dec 2012, 1(4):74-83

connection, Hailom (2008) explains the tendency of teachers toward the traditional lecture method. $\mathrm{He}$ stresses that many teachers perceived teaching as a transmission process where the teacher transmits knowledge to students and the students receive that knowledge based on a specified official syllabus.

On the other hand, Bennet et al. (2006) noticed that most students fall into the "old" curriculum and expect their instructors to lecture to them in a traditional classroom manner. Sometimes, it is observed that students categorize teachers who initiated them to practice active learning in the class as either not well prepared or incompetent. The question here is why instructors tend to use traditional methods of teaching. It is observed from their background information that most of them did not get training on active learning. Furthermore the classroom condition and the lack of resources force them to prefer lecture method.

The analysis and presentation of the data collected through classroom observation is presented below. To fulfill the purpose of the observation, three purposely selected instructors were observed. The data based on the requirement of the classroom checklist were collected. The observation was conducted by the researcher and his co-observer.

The data obtained from classroom observation proved that the classroom condition and seating arrangement is not convenient to implement active learning. One major problem observed in the classroom is the lay-out of the classes.A majority $(67 \%)$ of the observation result indicates that the classroom lay-out is not arranged to facilitate active learning. The physical environments of the classroom do not reflect the required condition for active learning practices.

In addition, a majority of the activities expected to be practiced by the instructors were not observed. For instance, $100 \%$ of the observed classes did not show the use of different instructional methods to implement active learning. In the interview conducted with the instructors, some of the instructors confirmed that applying all the activities in classroom is difficult. This indicates that the instructors implement the traditional/teacher fronted approach to teaching. The reasons for not applying the activities may be due to lack of training on active learning and classroom conditions such as large class size and fixed desks. 
Moreover, the observation shows that students were not portraying the required behavior for their own learning. Among nine observed sessions, only $33 \%$ of them were observed discussing issues in their groups. The main reason for their poor participation may be the failure of their instructors to use active learning in their respective classes.

Availability of instructional materials in classroom is the major factor to enhance the whole process of education. However, the observation result indicates that in $78 \%$ of the observed classes, there was no instructional material. Moreover, in $100 \%$ of the observed classes, the instructors did not use instructional materials. To sum up, the utilization of instructional materials in the observed classes was found to be at a minimum level. This is might be due to lack of resources.

Further, the observation indicates that all classroom activities are not well performed by the instructors. For example, many instructors do not give group work activities, ask questions or give exercises. Furthermore, almost all of the instructors do not follow up students' participation and activities. According to the observation result, only $33 \%$ of the instructors check and give constructive feedback to students' work. In an active learning classroom however, classroom assessment motivates the learners towards their learning (TESO, 2003).

In general, although they lack the necessary commitment to implement active learning, the instructors in the University seem to be aware of the importance of active learning. Thus, it can be concluded that the instructors perceived active learning positively. Active learning is practiced sometimes in the actual classes of the University. The quality and type of curriculum material is one major component in the implementation of active learning. But the finding of the study has shown that there is a shortage of teaching materials to be used in active learning classrooms. Concerning the factors that affect the implementation of active learning in the University instructors' tendency to favor traditional/lecture method, large class size, lack of recourses, shortage of time and lack of the teaching material are found to be the major ones.

\section{CONCLUSIONS}

The analysis of the data indicates that almost all of the participants of the study have perceived active learning positively. However, the extent of perception varies between the instructors. Moreover, it was indicated that the instructors were assured that when they use active learning, the students learn better and develop the ability to express their feelings confidently; they believe that active learning plays an important role in developing self-confidence; and those instructors who developed negative feeling towards active learning responded that active learning adds more work and requires additional effort. The analysis of the data disclosed that the extent of the practices of active learning in the University was found to be low. The instructors confirmed that they practice active learning in their classrooms "sometimes", which leads to the conclusion that the practices of active learning are low. On the other hand, the practices of active learning varied as indicated in the analysis of the data. Accordingly, most instructors used lecture method in their classrooms frequently which mean it is a teacher-centered method; discussion and group work are the two predominantly employed active learning strategies in the University next to lecture method; project work and peer-teaching are the third most commonly employed active learning methods; although problem solving strategy as an active learning method is believed to promote learners' critical thinking ability, it has been employed rarely; and field trip, role-playing and brain storming are not frequently employed in the University. The findings on twelve factors indicated how active learning is affected in various ways. The majority of the instructors asserted that students' lack of interest in participating in active learning greatly affected the implementation of active learning in their classrooms; other factors suggested as problems for the effective implementation of active learning were shortage of time and lack of resources; and large class size was also indicated as the major problem in implementing active learning.

\section{REFERENCES}

Aggarwal, J.C. (2006). Principles, Methods and Techniques of Teaching, New Delhi, SN Printers.

Bennett, C., Foreman-Peck, L. and Higgins, C.(2006). Researching in to Teaching Methods in Colleges and Universities. London: Kogan Page.

Bonwell, C and Elison, A. (2003). Active Learning Creating Excitement in the Classroom. Rhen: Grips.

Derebssa, D.S. (2006). Tension between traditional and modern teaching-learning approaches in Ethiopian primary schools. Journal of International Cooperation in Education 9(1):123-140.

Farant, J.S. (2000). Principles and Practice of Education (New Edition). Singapore: Longman. 


\section{Aschalew Teshome}

Frazee, M.B. (2005). Integrated teaching methods: theory, classroom approach and field based connections. New York: Mc Graw Hill Inc.

Hailom Banteyerga. (2008). Explorations towards an Alternative Model in Teacher Education Classroom in focus in quality Education in Ethiopia, Visions of 21st Century. Addis Ababa: IER.

ICDR. (2009).Teacher Education Hand Book. Addis Abba Finfine Printing and Publishing.

Leu, E. (2006). Quality of education and teacher learning: A Review of the literature. Washington, DC: USAID educational quality improvement project 1.

Leu, E. (2008). Designing Integrated Curriculum Materials for Primary Education: a Paper Presented at the Workshop in Oromia Education Bureau. (Unpublished)

Melese, B. (2009). Active learning: Notions, methods and examples. Finfinee: Oromia Education Bureau.

Ministry of Education (MoE). (2001). Indicators of the Ethiopian education system. Addis Ababa: Ministry of Education.
Sci. Technol. Arts Res. J., Oct-Dec 2012, 1(4):74-83

Ministry of Education (MoE). (2002). The education and training policy and its implementation. Addis Ababa: Ministry of Education.

MOE. (2003). TESO Pre Service Committee a Notional Curriculum Guideline for pre-Service Teacher Education Programs. Addis Ababa (unpublished)

Nardos Abebe. (2000). Issues and methods and materials in teaching primary school subject. Addis Ababa. AAU.

Oli, N. ( 2006). The status of active learning approach in the teacher education Colleges of Ormia Region. (Unpublished M.A Thesis). Addis Ababa University.

Silberman, M. (2006). Active Learning: 101 Strategies to Teach any Subject. Boston: Allyn and Bacon.

Squazzin, T. and Grann, M.V. (2008). Education Reform and Innovations in Namibia. Okahandja: Namibia.

TESO. (2003). Teacher Education System Overhaul Programme. Addis Ababa.

University Capacity Building Program (2009). University capacity building program and student enrollment in higher education. Available at www.ucbp-ethiopia.com (accessed 24/06/2010). 